\title{
ПРОБЛЕМА СУЩЕСТВОВАНИЯ «ТОРГОВОГО ПУТИ ГЕРОДОТА»: ИСТОРИОГРАФИЧЕСКИЙ АСПЕКТ
}

\section{(C) 2020 г. Е.В. Вильданова}

Целью данной статьи является анализ и обобщение литературы по вопросу о существовании «торгового пути Геродота». Рассматривается проблема наличия и маршрута торгового пути на Южный Урал. Автором сделан вывод о существовании пути из западных земель на Южный Урал. Кроме того выделены спорные моменты по вопросу о начальной точке маршрута данного пути и месте изготовления импортируемых товаров.

Ключевые слова: археология, ранние кочевники Южного Урала, «торговый путь Геродота», скифский торговый путь, Северное Причерноморье, скифские бронзовые зеркала.

\section{THE ISSUE OF EXISTENCE OF THE «HERODOTUS TRADE ROUTE»: A HISTORIOGRAPHIC ASPECT}

\section{E.V. Vildanova}

The purpose of the paper is to analyze and summarize the bibliography about the existence of the «Herodotus trade route». The issue of the availability and route of the trade way to the South Urals are considered. It has been concluded by the author that there was a route from the western lands to the South Urals. Besides the controversial aspects have been highlighted regarding the starting point of the route of this way and the place of manufacture of imported products.

Keywords: archaeology, early nomads of the Southern Urals, «Herodotus trade route», scythian trade route, Northwest Black Sea Coast, scythian bronze mirrors.

В истории изучения взаимодействия кочевников Южного Урала с внешним миром принято выделять два основных направления - юго-восточное и западное, связанное с районами Северного Причерноморья, Северного Кавказа. Традиционно рассмотрение западного направления связей начинают с вопроса о существовании торгового пути на Южный Урал.

О торговом пути мы знаем еще со времен Геродота. В исторической литературе утвердилось мнение о том, что Геродот в IV книге «История» описывает именно торговый путь, соединяющий Северное Причерноморье и Южный Урал, хотя прямого указания на то, что путь именно торговый, автор не дает.

Геродот дает краткое описание царских владений скифов, далее указывает народы, проживающие за рекой Танаис. Больше информации дается об аргиппеях, проживающих у подножия высоких гор. Эти горы большая часть исследователей соотносит с Уральскими горами. По сообщению Геродота, к аргиппеям «иногда приходят скифы» и «ведут с ними переговоры при помощи семи толмачей на семи языках». Вместе с тем автор «Истории» отмечает, что сведения об аргиппеях «можно легко получить не только от скифов, но и от эллинов из Борисфенской торговой гавани и прочих понтийских городов». Таким образом, Геродот не указывает на существование именно торгового пути, он лишь отмечает, что скифы и эллины знали о локализации аргиппеев (Геродот, 2004, с. 176-177).

Мысль о возможном существовании и функционировании торгового пути из Ольвии впервые была высказана Б.Н. Граковым в 1947 году. «История» Геродота и археологические данные выступали в качестве подтверждения данного предположения. В качестве археологических источников автор приводит зеркала «ольвийского» типа VI-V вв. до н. э. из районов Бузулука и Орска и крестообразную бляху в Зуевском могильнике ананьинской культуры. «Ольвийские» зеркала имеют по краю невысокий бортик и боковую ручку. Ручка с продольными канелюрами и иногда украшена косой насечкой «елочкой», либо круглореберная, на конце которой помещена фигурка зверя, обычно барана, барса или пантеры. Крестовидные бляхи представляют собой четыре круга, один из них в центре, и удлиненный четырехугольный конец начинается от свободного края центрального круга. Такие бляхи оформлены в зверином стиле (Граков, 1947, с. 28-35).

«Ольвийскими» зеркала назвал Б.В. Фармаковский, предполагая, что они производились 
в первую очередь в Ольвии, а также в других колониях по северному берегу Черного моря. По вопросу места производства зеркал Б.Н. Граков придерживался аналогичного мнения (Фармаковский, 1914, с. 27).

По предположению Б.Н. Гракова, торговый путь шел из Ольвии, пересекал Дон, по Волге шел на север, подходил к южным отрогам Урала и там заканчивался. Б.Н. Граков считал, основываясь на сходстве орудий и украшений срубной и андроновской культур и на находках срубных сосудов в Западном Казахстане, что данный путь существовал еще в доскифскую эпоху. Автор также отмечает, что в восточных землях бывали только скифы, которые поставляли восточные товары в греческие города, таким образом эллины и узнали о землях и населении на востоке (Граков, 1947, с. 25).

На Ольвию, в качестве места производства вышеуказанных бронзовых зеркал и крестовидных блях, указывал и Н.Н. Бондарь. Ольвия, по мнению автора, занимала преобладающее место в торговых контактах Скифии. Торговые же связи с Кавказом, Поволжьем и Приуральем были не столь оживленными, о чем свидетельствует малочисленность находок импортных предметов на указанных территориях (Бондарь, 1955, с. 59, 73).

Ольвия выступает местом производства зеркал, украшенных в скифском стиле, и у М.В. Скржинской. Зеркала выступали в качестве предмета торгового обмена и представляли ценность не только как искусное изделие, но и как слиток бронзы (около 700-800 г). Такие зеркала и ольвийские монеты - борисфены, найденные по пути на Урал, являются непосредственными свидетельствами контактов ольвийских купцов и савроматского населения (Скржинская, 2001, с. 90).

Изучением торговых связей кочевников занимался и К.Ф. Смирнов. Привлекая данные Геродота, К.Ф. Смирнов показывает скифский торговый путь, в ходе которого происходил товарообмен с кочевыми племенами. По его мнению, данный торговый путь проходил через Средний Дон, затем пересекал лесостепной зону между Доном и Волгой и далее вдоль заволжских рек попадал на Бузулук, а оттуда на Урал (Смирнов, 1964, с. 259).

Этой же проблеме посвятила свою работу Н.Л. Членова, которая помимо сведений Геродота и анализа археологических данных привлекала карту Птолемея и различные этнографические источники. Исследовательница дополнила археологические данные находка- ми в Поволжье еще двух зеркал «ольвийского» типа. По мысли автора, эти два зеркала, вероятно, не связаны с местным памятником, а представляют собой клад, зарытый на этом «торговом пути». Высказывается предположение, что клад мог быть оставлен человеком, который вез их для обмена (Членова, 1983, с. 51). В пользу предположения, что «торговый путь» шел на Урал из Причерноморья, свидетельствует и тот факт, что он существовал и ранее. Н.Л. Членова предположила, что в срубно-андроновскую эпоху путь, описанный Геродотом (во всяком случае, его восточная часть), был путем за медью. Попутно андроновцы и срубники открыли здесь золото. В скифскую эпоху описанный Геродотом путь был в основном путем за золотом. В обмен на золото могли идти различные изделия скифского и греческого производства, в том числе и те ольвийские зеркала, по которым Б.Н. Граков и проследил этот путь (Членова, 1983, с. 48-67).

Напротив, B.М. Скуднова не поддерживает Б.Н. Гракова в вопросе о месте производства зеркал. Исследовательница указывает на находки скифских зеркал - с ручкой в центре диска - в тех же районах (по «торговому пути Геродота») и полагает, что торговые связи с Заволжьем возникли уже в VI в. до н. э., но не у Ольвии, а у скифов. Присутствие же скифских зеркал в греческих могилах Ольвии B.М. Скуднова объяснила тесными связями греческого населения со скифскими ремесленниками (Скуднова, 1962, с. 24-25).

В трудах Т.М. Кузнецовой был представлен иной подход к изучению этого пути. T.М. Кузнецова высказала точку зрения, согласно которой путь, описанный Геродотом, не являлся торговым; путь, маркированный зеркалами «ольвийского» типа, указывал на землю аргипеев и исседонов. Сами же зеркала в интерпретации Т.М. Кузнецовой являются так называемыми патерами - священными сосудами, связанными с культами Апполона и Диониса. Такие патеры изготовлялись мастерами, работавшими при храмах. Кроме того, исследовательница исключила роль скифов в распространении этих предметов. Появление скифов в Северном Причерноморье, напротив, привело к конфликту между ними и греками, что, в свою очередь, остановило распространение культовых предметов в землях лесостепного населения (Кузнецова, 1990, с. 90; Кузнецова, 1991). 
В пользу посредничества скифов в торговле греческого населения с племенами ранних кочевников Южного Урала высказывается А.В. Безруков. В качестве косвенного подтверждения исследователь приводит находки скифских псалиев, найденных у Ртищева и Бугуруслана, а также зеркал с ручками в виде фигурок животных (Безруков, 2003, с. 233). Исследовательницей Н.А. Лейпунской указывается на достаточно короткий период производства бронзовых предметов в зверином стиле. Часть таких вещей, вероятно, была предназначена именно для торговли со скифами. На территорию Южного Урала эти ценные предметы могли попасть по маршруту, описанному Геродотом, при помощи передачи от одного народа другому (Leypunskaya, 2007, с. 126-128).

В работе Е.В. Игуменшевой на основании малочисленности импортных предметов в комплексах ранних кочевников Южного Урала делается вывод об отсутствии устойчивых торговых связей с оседлыми соседями. Тем не менее полностью торговый обмен не отрицается (Игуменшева, 2011, с. 66-67).

С.Я. Ольговский, изучив все известные в настоящее время крестовидные бляхи, условно разделил их на две группы, которые характеризуют искусство двух областей - Среднего Поднепровья и Западного Причерноморья. Исследователь пришел к выводу, что нет никаких оснований считать местом производства таких блях Ольвию или Березань. Указывая на высокий уровень развития металлообрабатывающего ремесла в скифской Лесостепи, автор называет данный регион местом выработки формы этих украшений и местом изготовления первых экземпляров. Окончательное решение этого вопроса автор видит в обнаружении литейных форм для их изготовления или полуфабрикатов в конкретной мастерской (Ольговский, 2017б, с. 481-482).

С.Я. Ольговский также полагает, что последние исследования скифских ремесленных центров дают основания считать их более мощными и развитыми, чем считалось ранее. Греческие купцы были частыми гостями в этих центрах, но дальше на восток они не проникали, а скифы сами распространяли свою продукцию до Урала и Поволжья. По его мнению, «ольвийские» зеркала и крестовидные бляхи с элементами скифского звериного стиля не могут служить доказательством связей Ольвии с этими областями, так как не являются продукцией ольвийских литейщиков. Автор заключает, что торговый путь в восточные области существовал, но не из Ольвии, а из лесостепной левобережной Скифии. Однако ни зеркала «ольвийского» типа, ни крестовидные бляхи не могут служить подтверждением прибытия греческих купцов в Поволжье и на Урал, так как они не решались выезжать за пределы Скифии, о чем свидетельствует отсутствие античных вещей в северо-восточных памятниках (Ольговский, 2017a; 2017б).

Не согласен с данной точкой зрения В.Ю. Зуев. Зеркала «ольвийского» типа он предложил называть «борисфенитскими», по месту их вероятного производства - Борисфену. Вместе с тем исследователь допускает возможность производства таких зеркал и в Ольвии. Зеркала эти получили распространение в VI в. до н. э. Автор, основываясь на распространении зеркал борисфенитского типа, прослеживает транзитный караванный путь, который шел с запада на восток, в самобытный центр скифской культуры VII-VI в. до н. э. - Предкавказскую Скифию (Зуев, 2014, с. 91).

В работе, посвященной случайным находкам скифских зеркал эпохи архаики, исследователи И.А. Бажан и В.Ю. Зуев приводят несколько зеркал и ручек зеркал «борисфенитского» типа с пантерой и головой барана на рукояти, а также их аналогии на прилегающих территориях. Авторы заключают, что зеркала отлично детализируют картину торговых путей эпохи архаики. Особенно уточняя реальность существования торгового пути по степям центрального и восточного Крыма. Вновь подчеркивается, что зеркала с «келермесскими» пантерами отливались в Борисфене (о. Березань). По разным направлениям торговых путей, идущих сухопутными дорогами через степи, вероятнее всего из Ольвии, зеркала попали на запад - в Подолию, на север - в лесостепное Приднепровье и на восток по Боспорскому транзитному пути до Северного Кавказа, а оттуда - на северо-восток, в Поволжье и южное Приуралье (Бажан, Зуев, 2014, c. 5-12).

В 2018 году вышла еще одна статья В.Ю. Зуева, где к зеркалам «борисфенитского» типа автором отнес 143 подобных зеркала. Эти зеркала были найдены на обширных пространствах евразийской степи. Исследователь разделил их на шесть серий (Зуев, 2018, c. 25). 
Таким образом, существуют две точки зрения по вопросу о происхождении зеркал «ольвийского» или «борисфенитского» типа. Согласно первой точке зрения, изготовлялись они в скифской Лесостепи и именно оттуда попали на территорию Южного Приуралья и в Поволжье. Согласно второй точке зрения, место изготовления подобных зеркал - остров Березань, откуда по торговому транзитному пути они попали в восточные области евразийской степи.

Исследователи А.Д. Таиров и К.Г. Коноплева полагают, что южноуральские кочевники со второй половины VI в. до н. э. включаются в обменные операции по «торговому пути Геродота» и становятся основными поставщиками металла в лесостепное и степное Причерноморье. С территории Южного Урала в основном экспортировалась медь, помимо нее вывозились, вероятно, золото и пушнина. Каменные жертвенники без ножек, а также жертвенники на двух-четырех ножках выступают в качестве подтверждения существования «торгового пути Геродота». В Среднем и Нижнем Подонье, в Поволжье, в лесостепной и степной Скифии, так же как и на Южном Урале, они известны в памятниках второй половины VI - V вв. до н. э. Причем исчезновение их во всех отмеченных регионах происходит практически одновременно. Исследователи проанализировали характер распространения жертвенников и пришли к выводу, что во всех районах, если по ним имеются данные спектроаналитического анализа цветного металла, зафиксирован металл южноуральского происхождения. Эти же районы примыкают либо к «торговому пути Геродота», либо к «торговой» артерии Среднее Поволжье - Северный Кавказ. В итоге каменные жертвенники могут служить маркерами связей населения различных районов восточноевропейской степи и лесостепи с кочевниками Южного Урала (Таиров, Коноплева, 2012, с. 86).

В настоящее время в научной литературе сложился ряд мнений по вопросу существования пути из западных областей в восточные евразийские степи. Ряд ученых, основываясь на данных Геродота и опираясь на археологические источники, полагают, что торговый путь все же существовал. Спорным моментов в данном случае является начальная точка маршрута и вопрос о производстве продукции (зеркал, крестовидных блях). В настоящее время в качестве исходных пунктов указывают либо земли Лесостепной Скифии, либо Северное Причерноморье, сама продукция либо изготовлялась непосредственно скифами или же производилась мастерами из Северного Причерноморья. Решение данного вопроса видится исследователям в обнаружении литейных форм и заготовок. Таким образом, путь из западных областей на Южный Урал действительно существовал и, возможно, являлся торговым путем, по которому в евразийские степи попадали товары из западных областей. Данные же спектроаналитического анализа цветного металла свидетельствуют о существовании экспорта сырья с южноуральских территорий.

\section{ЛИТЕРАТУРА}

Бажан И.А., Зуев В.Ю. Случайные находки скифских зеркал эпохи архаики в Северном Причерноморье // Материалы по археологии и истории античного и средневекового Крыма. 2014. № 6. С. 5-29.

Безруков А.B. К вопросу о торговых коммуникациях в Южном Приуралье по данным письменных и археологических источников (VI-IV вв. до н.э.) // Проблемы истории, филологии, культуры (ПИФК). 2003. №13. C. 229-236.

Бондарь Н.Н. Торговые отношения Ольвии со Скифией VI-V вв. до н.э. // CA. XXIII. / Отв. ред. Б.А. Рыбаков. М.: Изд-во АН СССРб 1955. С. 58-80.

Геродот. История в 9 кн. Пер. с греч. и комм. Г.А. Страновский. М.: Олма-Пресс Инвест, 2004. 640 с.

Граков Б.Н. Чи мала Ольвія торговельні зносини з Поволжям і Приураллям в архаічну і класичну епохи? // Археологія. 1947. Т. І. С. 23-38.

Зуев В.Ю. Боспорский транзитный путь распространения греческих зеркал в эпоху архаики (по материалам погребальных памятников и случайных находок) // Погребальная культура Боспорского царства. Материалы Круглого стола, посвящённого 100-летию со дня рождения Михаила Моисеевича Кубланова / Отв. Ред. В.Ю. Зуев, В.А. Хршановский. СПб.: Нестор-История, 2014 . С. 66-94.

Зуев В.Ю. Первая серия зеркал борисфенитского типа // Материалы Междун. науч. конф. «Боспорский феномен. Общее и особенное в историко-культурном пространстве античного мира»(СанктПетербург, 28 - 30 ноября 2018). Ч. ІІ. / Отв. ред. В. Ю. Зуев, В.А. Хршановский. СПб.: ИПЦ СПбГУПТД, 2018. C. 25-47. 
Игуменшева E.B. Пути проникновения импортных изделий на территорию Южного Приуралья в «савроматскую» и раннесарматскую эпохи (историография проблема) // РА. 2011. № 1. 2011. С. 62-67.

Кузнецова T.M. Торговые или священные пути греков? // Проблемы скифо-сарматской археологии / Отв. ред. А.И. Мелюкова. М.: Наука, 1990. С. 86-90.

Кузнецова Т.М. Этюды по скифской истории. М.: ИА АН СССР, 1991. 150 с.

Ольговский С.Я. О караванном пути из Ольвии на Урал и в Поволжье и вопросы происхождения зеркал и крестовидных блях // Археология Евразийских степей. 2017. №3. С. 209-223.

Ольговский С.Я. Существовал ли караванный путь из Ольвии на Урал и в Поволжье в архаическую эпоху // Старожитності раннього залізного віку / Археологія і давня історія України: Вип. 2 (23). К.: Інститут археології НАН України, 2017б. С. 476-483.

Скржсиская М.В. Скифия глазами эллинов. СПб.: Алетейя, 2001. 304 с.

Скуднова В.M. Скифские зеркала из архаического некрополя Ольвии // Культура и искусства античного мира. Вып. 3. / ТГЭ. Т. VII. Л.: Изд-во ГЭ 1962. С. 5-27.

Смирнов К.Ф Савроматы (ранняя история и культура сарматов). М.: Наука, 1964. 379 с.

Таиров А.Д., Коноплева К.Г. Каменные жертвенники как источник по связям кочевников Южного Урала со скифским миром // Вестник ЮУрГУ. Серия «Социально-гуманитарные науки». 2012. № 10 (269). С. 86-87.

Фармаковский Б.В. Архаический период в России // МАР. 1914. № 34. С. 15-78.

Членова Н.Л. Предыстория «торгового пути Геродота» (из Северного Причерноморья на Южный Урал // СА. 1983. №1. C. 47-65.

Leypunskaya N.A. Olbian-Scythian Trade: Exchange Issues in the Sixth to Fourth Centuries BC // Classical Olbia and the Scythian World: From the Sixth Century BC to the Second Century AD / D. Braund and S.D. Kryzhitskiy (Ed.). Oxford: Oxford University Press, 2007. P. 121-133. DOI:10.5871/ bacad/9780197264041.003.0009

\section{Информация об авторах:}

Вильданова Елена Владимировна, Оренбургский государственный педагогический университет (г. Оренбург, Россия); vildanovaelena@inbox.ru

\section{REFERENCES}

Bazhan, I. A., Zuev, V. Yu. 2014. In Materialy po arkheologii i istorii antichnogo i srednevekovogo Kryma (Materials on the Archaeology and History of the Ancient and Medieval Crimea) 6., 5-29 (in Russian).

Bezrukov, A. V. 2003. In Problemy istorii, filologii, kul'tury (Journal of Historical, Philological and Cultural Studies) 13, 183-193 (in Russian).

Davydova, A. V. 1955. In Rybakov, B. A. (ed.). Sovetskaia Arkheologiia (Soviet Archaeology) 23. Moscow: Academy of Sciences of the USSR, 58-80 (in Russian).

Gerodot. Istoriia v 9 knigakh (Herodotus. History in 9 books). 2004. Moscow: "Olma-press Invest" Publ. (in Russian).

Grakov, B. N. 1947. In Arkheologiia (Archaeology) I, $23-38$ (in Ukranian).

Zuev, V. Yu.2014. In Zuev, V. Yu., Khrshanovski, V. A. (eds.). Pogrebal'naja kul'tura Bosporskogo carstva (Sepulchral culture of the Bosporan kingdom) Saint Petersburg: Nestor-Istoriia” Publ., 66-94 (in Russian).

Zuev, V. Yu.2018. In Zuev, V. Yu., Khrshanovski, V. A. (eds.). Materialy Mezhdunarodnoi nauchnoi konferentsii "Bosporskii fenomen. Obshhee i osobennoe v istoriko-kul turnom prostranstve antichnogo mira" (Sankt-Peterburg, 28-30 noiabria 2018 g.) (Proceedings of International Research Conference "Bosporus phenomenon. General and Special within the Historical and Cultural Space of the Ancient World") (Saint Petersburg, November 28-30, 2018)) 2. Saint Petersburg: Saint Petersburg State University of Industrial Technologies and Design, 25-47 (in Russian).

Igumensheva, E. V. 2011. In Rossiiskaia Arkheologiia (Russian Archaeology). (1), 62-67 (in Russian).

Kuznetsova, T. M. 1990. In Melyukova, A. I. (ed.). Problemy skifo-sarmatskoi arkheologii (Issues of Scythian-Sarmatian Archaeology). Moscow: "Nauka" Publ., 86-90 (in Russian).

Kuznetsova, T. M. 1991. Etyudy po skifskoi istorii (Etudes on Scythian History) Moscow: Institute of Archaeology, USSR Academy of Sciences (in Russian). 
Leypunskaya, N.A. 2007. In Braund, D. and Kryzhitskiy, S.D. (eds.). Classical Olbia and the Scythian World: From the Sixth Century BC to the Second Century AD. Oxford: Oxford University Press, 121-133. DOI:10.5871/bacad/9780197264041.003.0009

Olgovsky S. Ya. 2017. In Arkheologiia Evraziiskikh stepei (Archaeology of Eurasian Steppes) 3. 209-223 (in Russian).

Ol'govsky, S. Ya. 2017. In Arkheologiia i davnia istoriia Ukraïni (Archaeology and Ancient History of Ukraine) 2 (23). Kiev: Institute of Archaeology of the National Academy of Sciences of Ukraine, 476-483 (in Russian).

Skrzhinskaya, M. V. 2001. Skifiya glazami e'llinov (Scythia through the Eyes of the Hellenes). Saint Petersburg: "Aleteiia” Publ. (in Russian).

Skudnova, V. M. 1962. In Kultura i iskusstvo antichnogo mira (Culture and Arts of the Ancient World) 3. Series: Transactions of the State Hermitage Museum VII. Leningrad: State Hermitage Museum Publ., 5-27 (in Russian).

Smirnov, K. F. 1964. Savromaty. Ranniaia istoriia i kul'tura sarmatov (Sauromatians. Early History and Culture of Sarmatians). Moscow: "Nauka" Publ. (in Russian).

Tairov, A. D., Konopleva, K. G. 2012. In Vestnik IuUrGU. Seriia «Sotsial'no-gumanitarnye nauki» (Bulletin of South Ural State University. Series: Social and Humanitarian Sciences). 10, 86-87 (in Russian).

Farmakovsky, B. V. 1914. In Materialy po arkheologii Rossii (Proceedings for the Archaeology of Russia) 34., 15-78 (in Russian)

Chelova, N. L. 1983. In Sovetskaya arkheologiya (Soviet Archaeology) 1. 47-65 (in Russian).

\section{About the Author:}

Vildanova Elena V. Orenburg State Pedagogical University. Sovetskaya, Str., 19, Orenburg, 460014, Russian Federation; vildanovaelena@inbox.ru 